23

\title{
Оценка усталостных повреждений в органическом стекле оптическими методами
}

\author{
() А.П. Владимиров ${ }^{1,4}$, И.С. Каманцев ${ }^{1}$, Н.А. Друкаренко ${ }^{1}$, В.Н. Тришин $^{1,4}$, Л.А. Акашев ${ }^{2}$, А.В. Дружинин ${ }^{3,4}$ \\ ${ }^{1}$ Институт машиноведения Уральского отделения РАН, \\ 620049 Екатеринбург, Россия \\ ${ }^{2}$ Институт химии твердого тела Уральского отделения РАН, \\ 620990 Екатеринбург, Россия \\ ${ }^{3}$ Институт физики металлов Уральского отделения РАН, \\ 620108 Екатеринбург, Россия \\ ${ }^{4}$ Уральский федеральный университет, \\ 620002 Екатеринбург, Россия \\ e-mail: vap52@bk.ru
}

Поступила в редакцию 14.06.2018 г.

В окончательной редакции 17.06.2019 г.

Принята к публикации 18.07.2019 г.

По фрагментам усредненных во времени спекловых изображений, зарегистрированных без остановки циклических нагружений, изучены особенности зарождения, старта и распространения трещины в объеме прозрачного призматического образца с острым V-образным надрезом. Показано, что первые признаки усталостных повреждений появляются не на вершине надреза, а на расстоянии $400 \mu \mathrm{m}$ от нее в центре образца на участке диаметром $200 \mu \mathrm{m}$. После начала развития („старта“) трещины размер зоны необратимых процессов увеличивается на порядок. По изменению спекловых изображений и методом эллипсометрии изучено распределение показателя преломления и плотности вокруг трещины. Показано, что максимальное значение относительного изменения плотности, не менее $2 \cdot 10^{3}$, находится вблизи трещины. Спекловый метод может быть базой для создания средств и методик неразрушающего контроля, позволяющих по скорости изменения и предельных значениях показателя преломления и плотности материала, а также других параметров, влияющих на изменение оптических путей волн на малых участках порядка $10 \mu \mathrm{m}$, оценивать время до старта трещины.

Ключевые слова: органическое стекло, многоцикловая усталость, спеклы, спекловое изображение, эллипсометрия, предразрушение, старт трещины.

DOI: $10.21883 /$ OS.2019.11.48530.165-19

\section{Введение}

Установлено, что многоцикловая усталость материала является доминирующим фактором разрушения механических деталей и элементов конструкций [1-3]. В силу того, что до сих пор не существуют адекватные физические модели усталостного разрушения материалов, инженерная практика лишена методов оценки долговечности деталей и конструкций $[2,4,5]$. Такая ситуация во многом связана с отсутствием простых, надежных и однозначно интерпретируемых методов изучения процессов усталостного разрушения материала без остановки циклического нагружения.

Сразу же после создания лазеров и обнаружения пятнистой (спекловой) структуры рассеянного излучения появились публикации по спекл-интерферометрии усталостных явлений [6-8]. Однако из за высокой трудоемкости исследований, а также сложного характера изменения регистрируемых сигналов эти методы не нашли широкого применения.

Позже в работах [9-14] теоретически и экспериментально было показано, что указанные недостатки можно преодолеть, используя метод усредненных во времени спеклов. Суть метода заключается в том, что при формировании цифрового спеклового изображения объекта время экспонирования фотоприемников (например, телекамеры) выбирается кратным периоду его нагружения. В том случае, когда на поверхности объекта не происходят процессы, изменяющие ее рельеф, картина усредненных спеклов не изменяется во времени. Если же на какой либо стадии многоциклового нагружения объекта возникают необратимые изменения рельефа поверхности, то согласно [10] различие оптических путей рассеянных волн более чем на $1 \mathrm{~nm}$ приводит к изменению цифровой картины спеклов в сопряженной области. Этот метод был впервые использован в работах $[10,11]$ для качественного анализа процесса формирования усталостной трещины в металле. Было показано, что метод позволяет обнаружить область, в которой появляются первые признаки необратимого процесса, проследить эволюцию размера этой области вплоть до старта трещины. Кроме того, в этих работах предложена методика определения скорости развития усталостной трещины. 


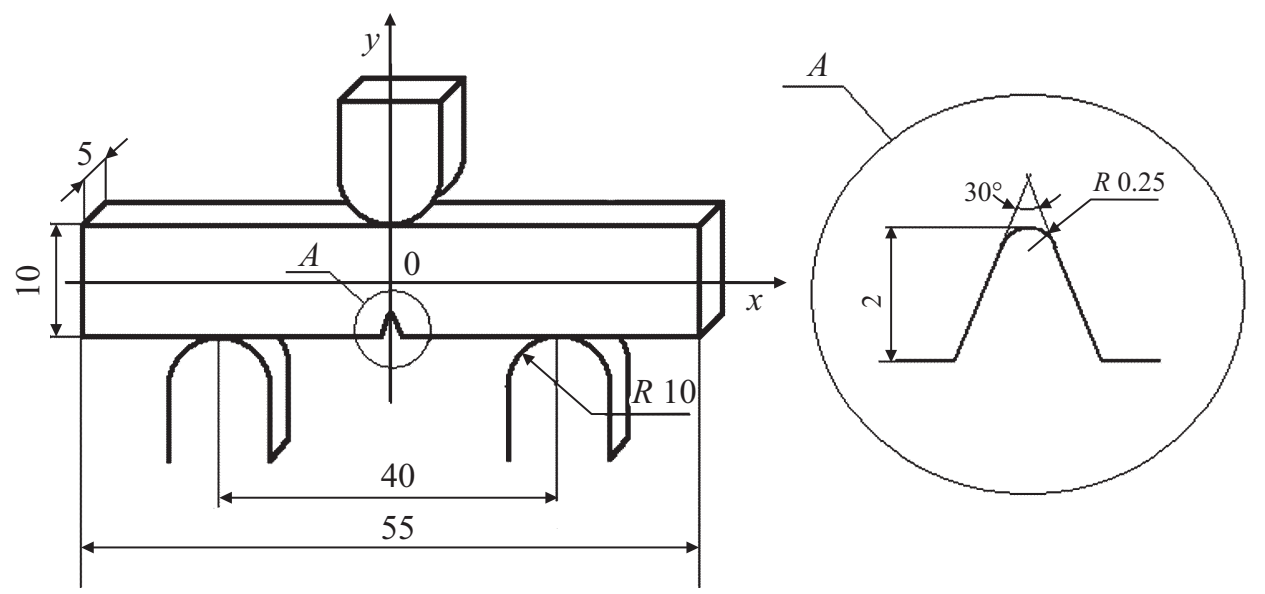

Рис. 1. Размеры образца и положения упоров при трехточечном изгибе.

Успешное применение спеклов для качественного анализа деградации поверхности образца при усталостных испытаниях ставит вопрос о возможности использования предложенной в $[10,11]$ методики для изучения процессов усталости, происходящих в объеме прозрачных объектов, с количественной оценкой деградации материала. Основной целью настоящей работы являлось изучение в реальном времени особенностей зарождения усталостной трещины в объеме образца с V-образным острым надрезом и сравнение полученных данных с процессами, протекающими в металлах на стадии зарождения трещины. Другой целью работы было определение при многоцикловой усталости предельных значений в изменении показателя преломления (плотности) оргстекла как материала, из которого изготавливаются иллюминаторы самолетов и вертолетов. Определение предельных значений физических величин, соответствующих старту трещины, определение размеров участков, где эти величины достигают предельных значений, актуально с точки зрения оценки остаточного ресурса для элементов конструкций. Определяя тем или иным способом скорость изменения физической величины на соответствующей базе измерения, зная предельное его значение, можно оценить время до старта трещины.

\section{Образцы и методика усталостных испытаний}

Объектами исследования были призматические образцы размером $5 \times 10 \times 55 \mathrm{~mm}$ из оргстекла марки „ACRUMA“ (рис. 1). С целью локализации области зарождения усталостной трещины на заранее известном месте на образец был нанесен острый V-образный надрез глубиной $2 \mathrm{~mm}$ и радиусом в вершине $0.25 \mathrm{~mm}$. Циклическое нагружение образцов проводили на высокочастотной резонансной испытательной машине „MIKROTRON“ Rumul по схеме трехточечного изгиба при частоте нагружения $\approx 100 \mathrm{~Hz}$. Мини-
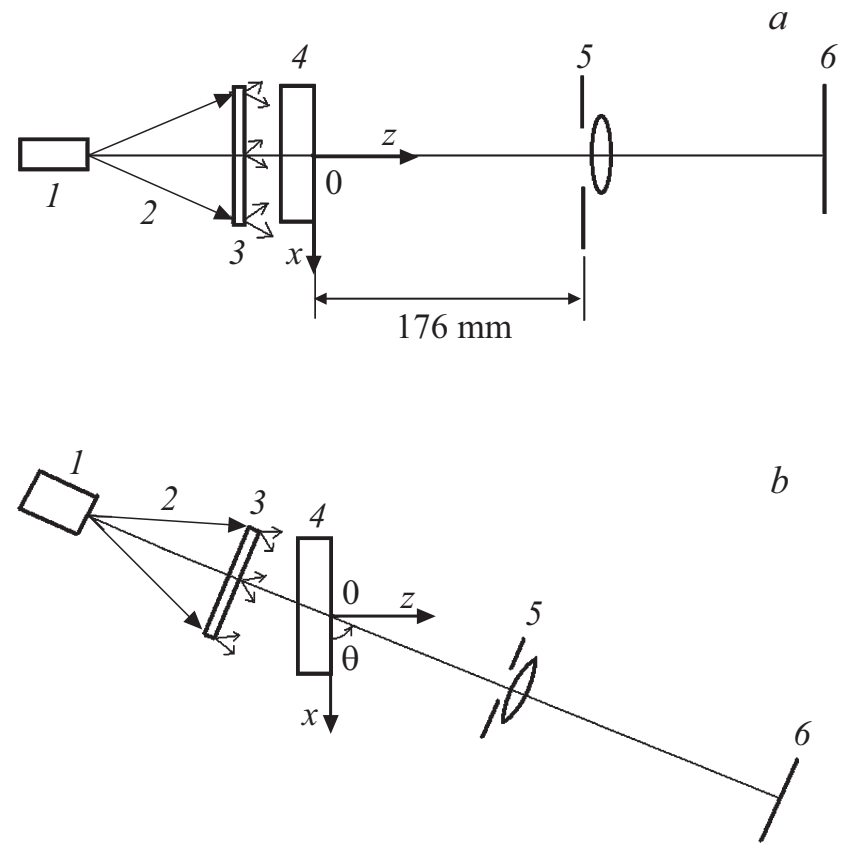

Рис. 2. Оптические системы для формирования спекловых изображений: $(a)$ при наблюдении по нормали к поверхности, $(b)$ при наблюдении под углом $\theta$ к оси $o x .1$ - лазерный модуль, 2 - лазерное излучение, 3 - матовый рассеиватель, 4 - образец, 5 - линза телекамеры, 6 - матрица телекамеры.

мальное и максимальное значения приложенного усилия изменялось в пределах от $3 \mathrm{~N}$ до $30 \mathrm{~N}$ соответственно.

Для регистрации спекл-полей были использованы оптические системы, схемы которых показаны на рис. 2. Картину спеклов регистрировали в плоскости изображения образца. Увеличение, формируемое оптической системой, равнялось 0.7. Диаметр диафрагмы у линзы 5 выбирался таким образом, чтобы минимальный размер спеклов был несколько больше размера пикселя матрицы телекамеры 6 . 
В экспериментах использовалась монохромная телекамера „Видеоскан 415M USB“ с матрицей, содержащей $782 \times 582$ фотоэлемента с размерами $8.3 \times 8.3 \mu \mathrm{m}$. Выбранное время экспозиции телекамеры соответствовало 50 циклам нагружения. Регистрацию кадров спекловых изображений в формате ВМР осуществляли через 1000-3500 циклов нагружения после стабилизации резонансной частоты испытательной машины. Изменение картины спекл-полей определяли с помощью коэффициента корреляции $\eta$ двух цифровых изображений одинакового размера. Цифровые изображения представляли собой двумерные матрицы, соответствующие одному и тому же участку кадра в разные моменты времени: в начальный момент времени $t_{1}$ и текущий момент времени $t_{2}$ при числе циклов нагружения $N_{1}$ и $N_{2}$ соответственно. Коэффициент корреляции $\eta$ находился по формуле:

$$
\eta=\frac{\frac{1}{n m} \sum_{i=0}^{n-1} \sum_{j=0}^{m-1}\left(A_{i j}-\bar{A}\right)\left(B_{i j}-\bar{B}\right)}{\left(\frac{1}{n m} \sum_{i=0}^{n-1} \sum_{j=0}^{m-1}\left(A_{i j}-\bar{A}\right)^{2}\right)^{1 / 2}\left(\frac{1}{n m} \sum_{i=0}^{n-1} \sum_{j=0}^{m-1}\left(B_{i j}-\bar{B}\right)^{2}\right)^{1 / 2}},
$$

где $i, j$ - номера элементов (пикселей) строки и номера строк матрицы соответственно, $n, m-$ число пикселей строки и число строк матрицы, $A_{i j}$ - числовое значение пикселя с номерами $i$ и $j$ при $t_{1}, B_{i j}-$ числовое значение этого пикселя в момент времени $t_{2}, \bar{A}-$ среднеарифметическая величина числовых значений элементов матрицы при $t_{1}, \bar{B}-$ среднеарифметическая величина числовых значений элементов матрицы в момент времени $t_{2}$.

Для мониторинга динамики необратимых процессов в режиме реального времени на экран компьютера через каждые $2 \mathrm{~s}$ выводили пространственное распределение величины $\eta$ в кадре изображения, найденное по массивам в $10 \times 10$ рх. Отсутствие взаимного перемещения элементов оптической системы до, во время или после испытания образца контролировали путем формирования спеклового изображения неподвижной части испытательной машины. Если в течение нескольких минут величина $\eta$, соответствующая неподвижной части, уменьшалась с единицы лишь до 0.97-0.99, то оптическая система считалась стабильной.

\section{Оптические методики}

В работе были использованы два оптических метода: метод динамической спекл-интерферометрии и поляризационно-оптический метод. Первый метод использовали для изучения в реальном времени накопления усталостных повреждений, а также для определения изменений показателя преломления среды. Второй метод использовался лишь для определения показателя преломления после снятия образца с испытательной установки.

\section{Динамическая спекл интерферометрия}

Теория динамики усредненных во времени спекловых изображений тонкого плоского прозрачного объекта, расположенного вблизи такого же тонкого неподвижного прозрачного диффузора, была опубликована в работе [12]. Кратко приведем основные положения этой работы.

Предполагается, что картина спеклов изменятся за счет трех процессов:

1) медленного поступательного перемещения образца вдоль оси $o x$ (рис. 2, $a$ ),

2) периодического колебания образца также вдоль оси $о x$ с фиксированной амплитудой и периодом $T$,

3 ) случайного изменения оптических путей волн, зондирующих объект исследования.

Согласно выбранной модели, волны со случайной начальной фазой сначала проходят через область объекта диаметром $2 a_{s}$ с центром в точке $A$, где $2 a_{s}$ - линейное разрешение линзы. Затем волны проходят сквозь малую диафрагму вблизи линзы и достигают точки $A^{\prime}$ в плоскости изображения объекта, сопряженной точке $A$. Оптическую длину пути для $j$-й волны определяем формулой

$$
u_{j}=\int_{l_{j}}\left[n_{j}(l)-n_{0}\right] d l,
$$

где $n_{j}(l)$ - распределение показателя преломления в фазовом объекте вдоль пути $j$-й волны, $l_{j}$ - длина пути $j$-й волны в объекте, $n_{0}$ - показатель преломления в отсутствие фазового объекта, интегрирование ведется вдоль пути волны.

В допущении, что все случайные величины независимы, а случайные значения разностей фаз пар волн коррелированны во времени, получено выражение для средней по времени интенсивности $\tilde{I}$ излучения и временной функции автокорреляции $R_{12}\left(t_{1}, t_{2}\right)$ этой интенсивности в произвольной точке $\mathbf{q}$ плоскости наблюдения:

$$
\begin{aligned}
R_{1,2}\left(t_{1}, t_{2}\right)= & I_{0}^{2} N(N-1) C_{0}^{2} \cos \left[\left(\left\langle x_{2}\right\rangle+\left\langle\tilde{x}_{2}\right\rangle-\left\langle x_{1}\right\rangle\right.\right. \\
& \left.\left.-\left\langle\tilde{x}_{1}\right\rangle\right)\right] e^{-\frac{1}{2} k_{11}-\frac{1}{2} k_{22}+k_{12}} e^{-\frac{1}{2} \tilde{k}_{11}-\frac{1}{2} \tilde{k}_{22}+\tilde{k}_{12}},
\end{aligned}
$$

где $I_{0}, N, C_{0}-$ константы, $x=k \mu, k=2 \pi / \lambda, \mu-$ средняя по области диаметром $2 a_{s}$ и по времени разность оптических путей пар волн, $\left\langle x_{1}\right\rangle$ и $\left\langle x_{2}\right\rangle$ средние по ансамблю объектов (ансамблю реализаций) значения $x$ в моменты времени $t_{1}$ и $t_{2}$ соответственно, $k_{11}$ и $k_{22}-$ дисперсия величины $x$ в моменты времени $t_{1}$ и $t_{2}$ соответственно, $k_{12}$ - временная функция автокорреляции величины $x$.

Величины $\left\langle\tilde{x}_{1}\right\rangle,\left\langle\tilde{x}_{2}\right\rangle, \tilde{k}_{11}, \tilde{k}_{22}, \tilde{k}_{12}$ в формуле (3) имеют тот же смысл, что и $\left\langle x_{1}\right\rangle,\left\langle x_{2}\right\rangle, k_{11}, k_{22}, k_{12}$. Однако они характеризуют изменение оптических путей пар волн, возникающее только из за движения шероховатой поверхности. 
Если шероховатость поверхности однородна, т.е. $\left\langle\tilde{x}_{2}\right\rangle=\left\langle\tilde{x}_{1}\right\rangle, \tilde{k}_{11}=\tilde{k}_{22}$, для нормированной автокорреляционной функции (3) получаем, что

$$
\eta\left(t_{1}, t_{2}\right)=\eta\left(u_{x}\right) \cos \left[\left(\left\langle x_{2}\right\rangle-\left\langle x_{1}\right\rangle\right)\right] e^{-\frac{1}{2} k_{11}-\frac{1}{2} k_{22}+k_{12}},
$$

где

$$
\eta=\eta\left(u_{x}\right)=e^{-\tilde{k}_{11}+\tilde{k}_{12}\left(u_{x}\right)}
$$

есть временная автокорреляционная функция, соответствующая перемещению прозрачной пластины в плоскости $x y$. Отметим, что формула (4) совпадает с аналогичной формулой, полученной в работе [13] для отражающего объекта. Следует отметить, что в работах $[13,15]$ была продемонстрирована корректность формулы (5). В эксперименте прозрачную пластину с известной шероховатостью (известным значением $\tilde{k}_{11}$ ) с шагом $0.1 \mu \mathrm{m}$ перемещали по оси $o x$. Было показано, что теоретическая и экспериментальная зависимости $\eta\left(u_{x}\right)$ совпадают в пределах $2.5 \%$.

Если шероховатость так мала, что $\eta\left(u_{x}\right) \cong 1$, а случайный процесс $x=x(t)$ стационарный, то $\left\langle x_{1}\right\rangle=\left\langle x_{2}\right\rangle$, $k_{11}=k_{22}$, и для нормированной функции (4) имеем

$$
\eta(\tau)=e^{-k_{11}+k_{12}(\tau)},
$$

где $\tau=t_{2}-t_{1}$. Если процесс $x=x(t)$ нестационарный, но время усреднения превышает время корреляции величины $x$, то

$$
\eta\left(t_{1}, t_{2}\right)=\cos \left[\left(\left\langle x_{2}\right\rangle-\left\langle x_{1}\right\rangle\right)\right] e^{-\frac{1}{2} k_{11}-\frac{1}{2} k_{22}} .
$$

Если нестационарный процесс $x=x(t)$ характеризуется дисперсиями $k_{11}$ и $k_{22}$, стремящимися к нулю, а $\left\langle x_{1}\right\rangle=0$, Tо

$$
\eta\left(t_{1}, t_{2}\right)=\cos \left\langle x_{2}\right\rangle \text {. }
$$

Пусть далее на контролируемом участке объекта показатель преломления не меняется по толщине $L$ образца, а его изменения имеют место лишь в направлении длины образца (ось $о x$ ). Если на участке градиент показателя преломления постоянен, то с учетом (2) вместо (8) имеем

$$
\eta=\cos \left[\left(\frac{2 \pi}{\lambda}\right) L \times \Delta n\right],
$$

где $\Delta n-$ разность показателя преломления на среднем, характерном расстоянии $\Delta x$ вдоль оси $о x$. Отметим, что $\Delta x \leq 2 a_{s}$. Следовательно, по формуле (9) можно определить величину $\Delta n$.

\section{Оптическая эллипсометрия}

Измерения показателя преломления стекла проводили нулевым методом на лазерном $(\lambda=633 \mathrm{~nm})$ эллипсометре ЛЗФ-3М при угле Брюстера для материала образца $\varphi_{B}=56.31^{\circ}$. Сначала с использованием компенсатора определялись азимуты поляризатора и анализатора в момент гашения светового пучка. Измерения эллипсометрических параметров $\Delta$ и $\psi$ проводили по четырем зонам, после чего их значения усреднялись. Для определения показателя преломления $n$ и коэффициента поглощения $\kappa$ полученные величины $\Delta$ и $\psi$ подставляли в систему уравнений (11) и (12):

$$
\begin{gathered}
n^{2}-\kappa^{2}=\sin ^{2} \varphi\left[1+\operatorname{tg}^{2} \frac{\cos ^{2}(2 \psi)-\sin ^{2}(2 \psi) \sin ^{2} \Delta}{(1+\sin (2 \psi) \cos \Delta)^{2}}\right] \\
2 n \kappa=\sin ^{2} \varphi \times \operatorname{tg}^{2} \varphi \frac{\sin 4 \psi \sin \Delta}{(1+\sin 2 \psi \cos \Delta)^{2}}
\end{gathered}
$$

Методы измерений подробно изложены в [16-18]. Первое измерение проводили на трещине, последующие с шагом $500 \mu \mathrm{m}$ влево и вправо от нее. Область усреднения соответствовала размеру светового пятна на поверхности образца $\sim 0.7 \mathrm{~mm}$.

\section{Результаты}

На рис. 3 приведены типичные распределения коэффициента корреляции $\eta$ спекловых изображений на разных стадиях испытания на усталость. Регистрацию изображений осуществляли по схеме, представленной на рис. 2, $a$, величину $\eta$ определяли по формуле (1) на участках размером $10 \times 10$ рх. Как видно по приведенным на рис. 3 данным, первые признаки необратимых процессов появляются на некотором расстоянии от вершины надреза. Анализируя данные, представленные на рис. 3, можно сделать вывод, что значительная часть дефектов находится вблизи вершины надреза и симметрична относительно оси $o z$. Вместе с тем следует подчеркнуть, что после старта трещины зона приращения величины $\eta$ перемещается вместе с трещиной.

Процедуру выявления и наблюдение развития объемных усталостных повреждений проводили на другом образце в следующей последовательности. Вначале по схеме, рис. 2, a, в режиме реального времени наблюдали распределение величины $\eta$ вблизи изображения надреза. При возникновении распределения, подобного тому, что представлено на рис. $3, b$, испытание в этой геометрии было прекращено. При визуальном осмотре образца макротрещины обнаружено не было. Анализ профилей поверхности, зарегистрированных оптическим профилометром до и после испытания с разрешением по высоте $\geq 3 \mathrm{~nm}$, позволяет сделать вывод об отсутствии каких либо изменений рельефа поверхности. После этого многоцикловые испытания образца были продолжено вплоть до разрушения, но регистрацию спекловых изображений осуществляли уже по схеме, представленной на рис. $2, b$. На рис. 4 приведены типичные распределения величины $\eta$, демонстрирующие развитие усталостных повреждений по толщине образца. Из представленных на рис. $4, b$ данных следует, что первые признаки необратимых изменений локализуются в центре образца с характерным размером $\approx 200 \mu \mathrm{m}$ на расстоянии от вершины надреза $\approx 400 \mu \mathrm{m}$. 

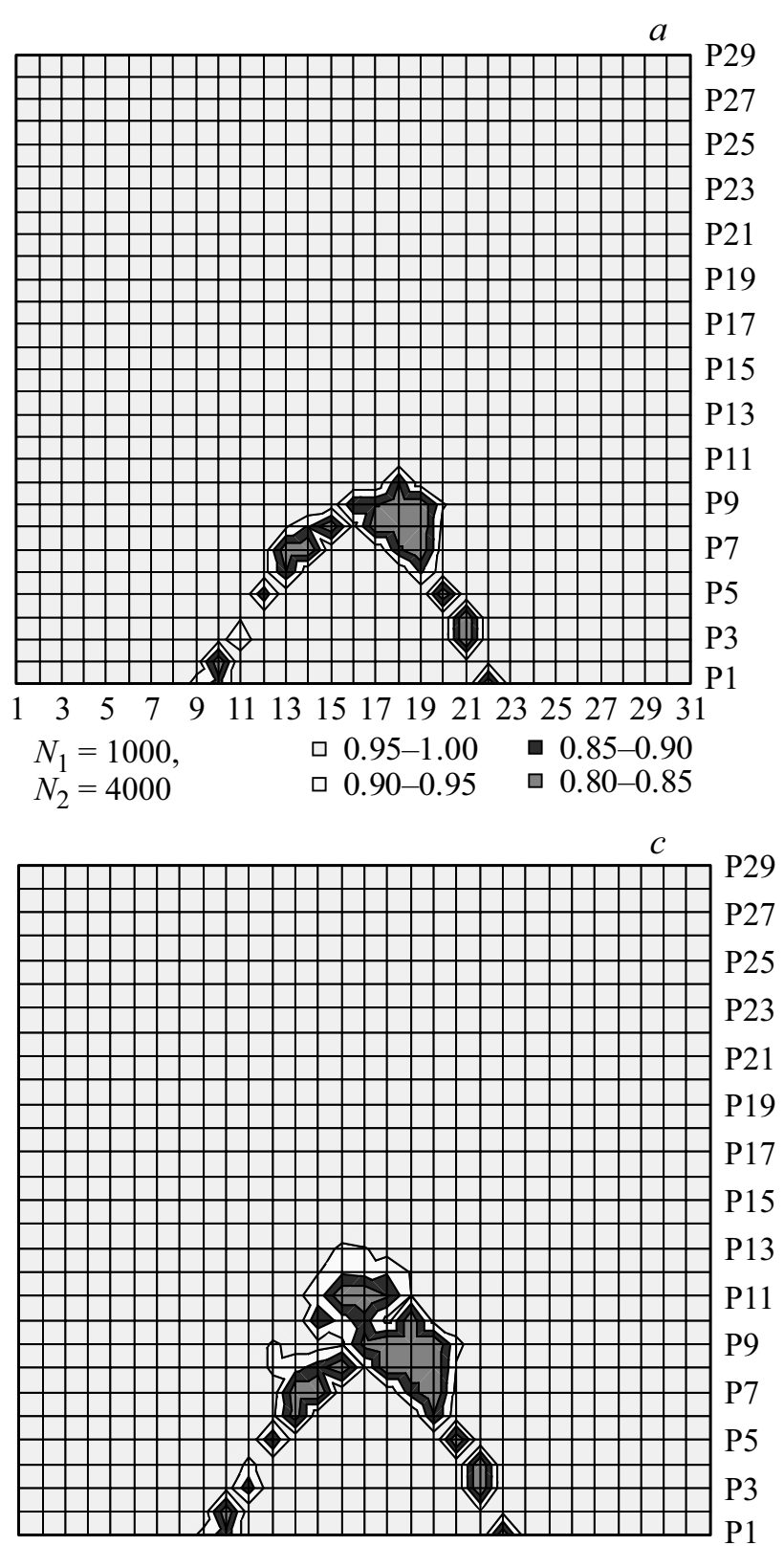
$\begin{array}{llll}1 & 3 & 5 & 7\end{array}$
$\begin{array}{lllllllll}15 & 17 & 19 & 21 & 23 & 252729 & 31\end{array}$
$N_{1}=1000$
$N_{2}=9000$
ㅁ $0.95-1.00$
- $0.85-0.90$
$0.90-0.95$
ㅁ $0.80-0.85$

91113

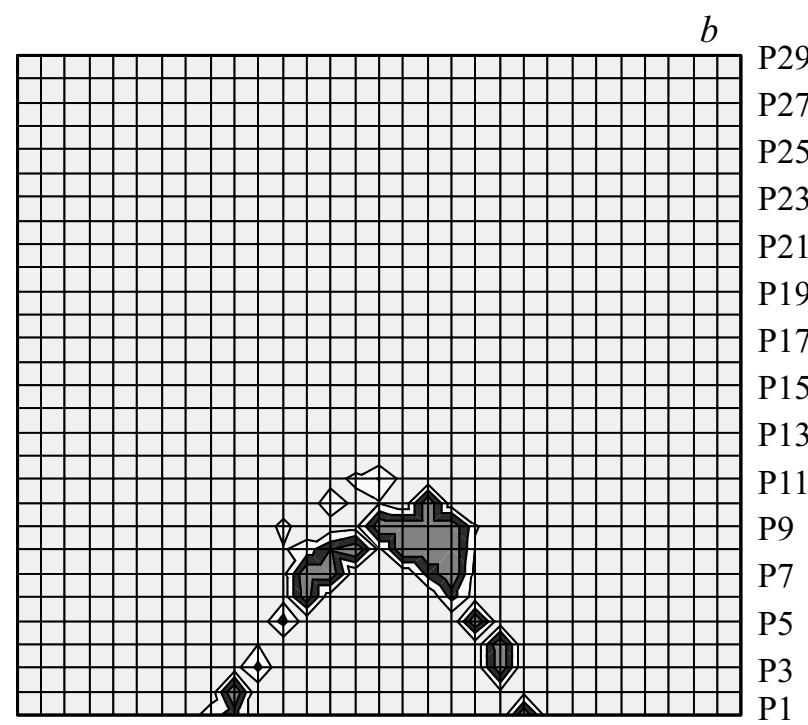
$\begin{array}{cccc}13579 \\ \\ N_{1}= & 1000, \\ & N_{2}=6000\end{array}$
15171921
$\square \quad 0.95-1.00$
$\square \quad 0.90-0.95$
25272931
ㅁ $0.80-0.85$

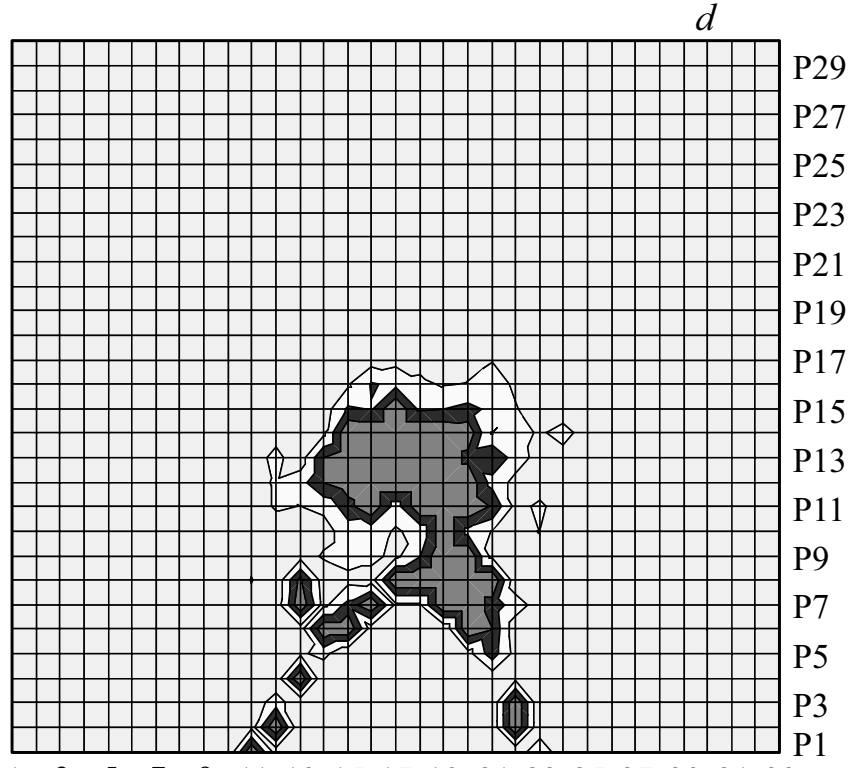

1

Рис. 3. Поле коэффициентов корреляции $\eta$ : $(a)$ до появления необратимых процессов, $(b)$ при первых признаках усталостных повреждений, $(c)$ до старта трещины, $(d)$ после старта трещины, где $N_{1}$ и $N_{2}$ - количество циклов нагружения для двух сравниваемых кадров.

По мере увеличения числа циклов нагружения левее на таком же расстоянии от надреза возникли близко расположенные второй и третий участки такого же размера (рис. $4, c)$. Далее при увеличении $N$ до 133000 изменение величины $\eta$ происходило в областях, соединяющих эти участки с краем надреза. В результате изучения этих изменений можно сделать вывод, что они неоднородны в пространстве (вдоль областей) и не синхронны во времени. Наибольшие изменения ло- кализуются на трех участках области: непосредственно вблизи надреза, примерно в середине полосы и в верхней ее части, т.е. на месте первоначального появления необратимых процессов (рис. $4, c d$ ). Начиная с $N=133000$ и до $N=135000$ циклов сначала слабые, затем значительные изменения величины $\eta$ возникли одновременно на указанных областях и в промежутке между ними (рис. 4,e). По видимому, данное явление можно рассматривать как завершающий акт перехода 


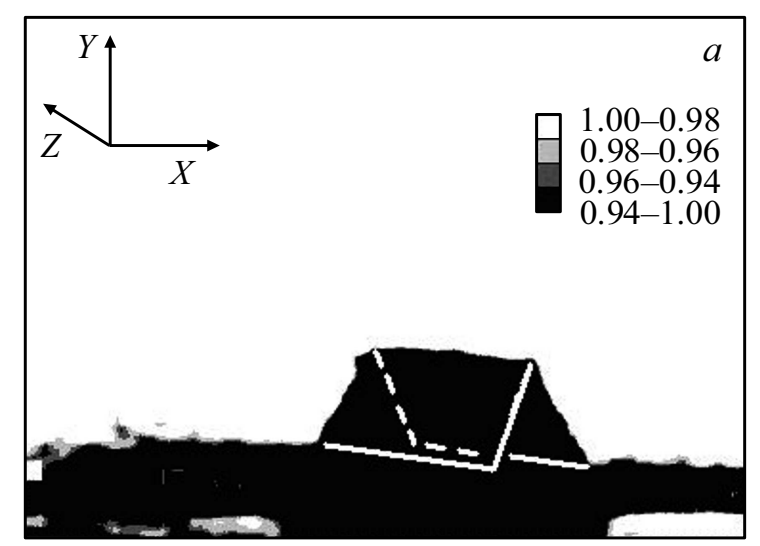

$N_{1}=119000, N_{2}=121000$

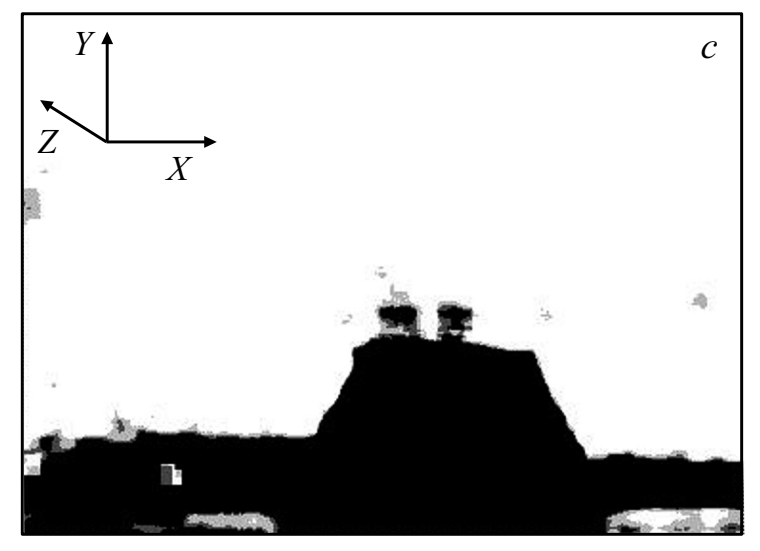

$N_{1}=126000, N_{2}=128000$

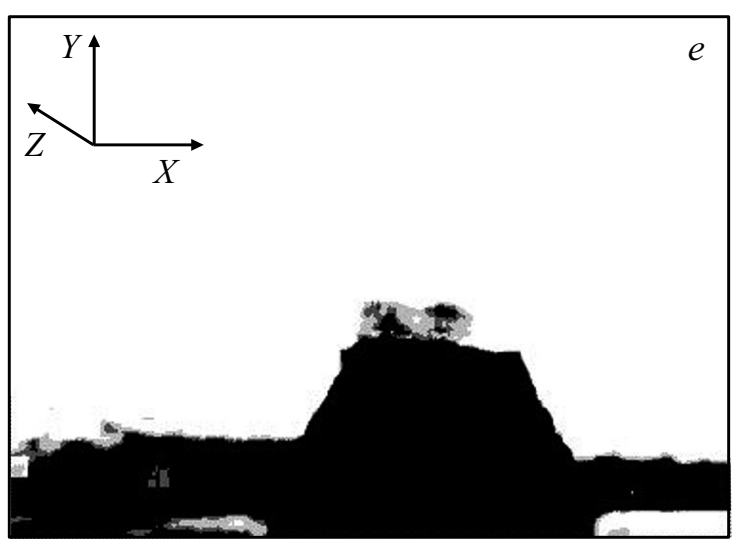

$N_{1}=133000, N_{2}=134000$

e

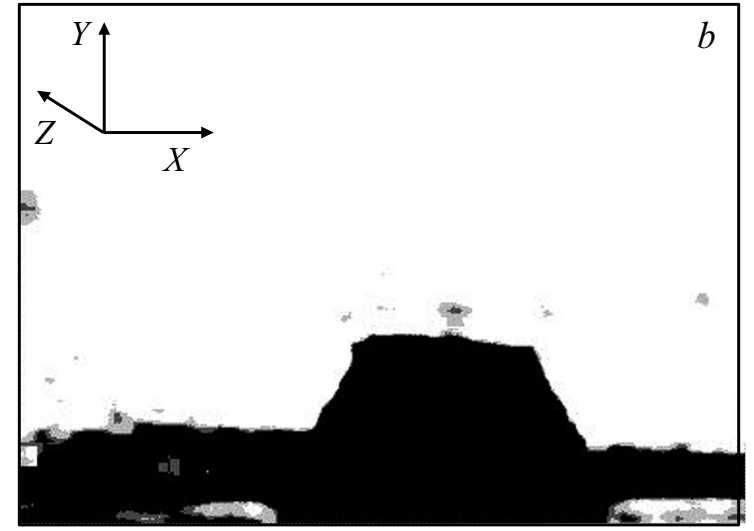

$N_{1}=126000, N_{2}=127000$

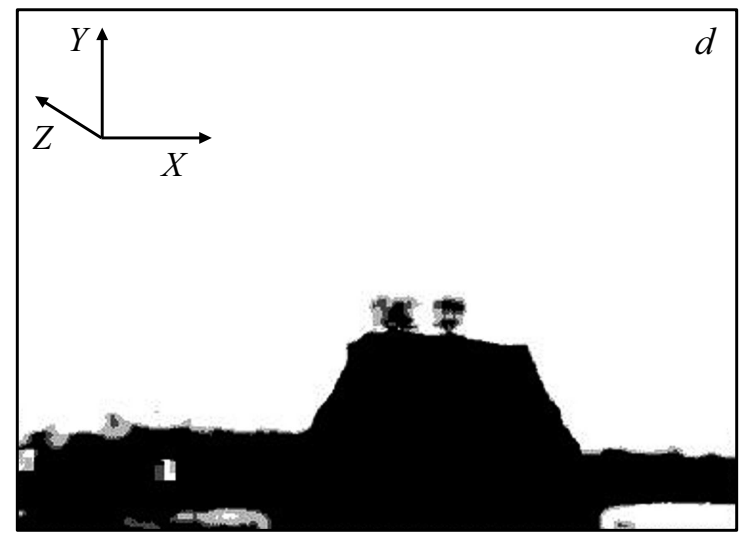

$N_{1}=129500, N_{2}=133000$

Рис. 4. Распределения величины $\eta$, демонстрирующие развитие усталостных повреждений по толщине образца.

материала из состояния предразрушения в состояние нарушения сплошности.

После 135000 циклов испытание образца было приостановлено, оптическая система вновь была перенастроена по схеме на рис. 2, $a$, затем испытание было продолжено. После стабилизации резонансной частоты образца было зафиксировано резкое увеличение размеров зоны, в которой имело место приращение величины $\eta$. Размер зоны увеличился с десятых долей до нескольких миллиметров. Далее в течение эксперимента наблюдалось медленное перемещение этой зоны по вертикали. После перемещения центра зоны примерно на $300 \mu \mathrm{m}$ испытание на усталость было завершено.

Визуальное наблюдение показало наличие трещины, которая охватывала половину толщины образца. Анализ трехмерных профилей поверхности вблизи трещины показал отсутствие изменений шероховатости и формы поверхности.

На рис. 5 показана типичная зависимость величины $\eta$ от координаты $x$, полученная по кадрам, соответ- 


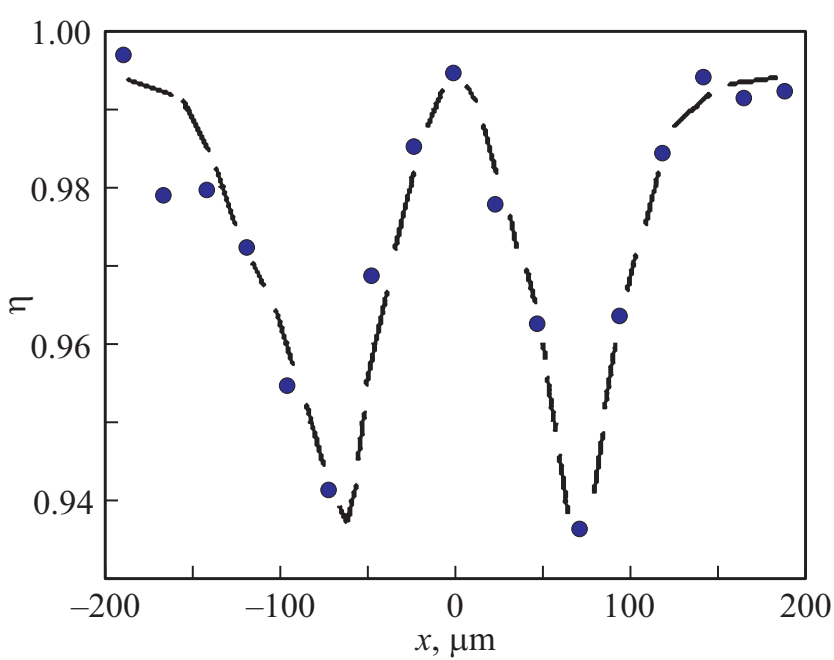

Рис. 5. Результат сканирования участком в $4 \times 4$ рх через изображение оптической неоднородности в системе координат рис. 1.

ствующим стадии формирования трещины. Зависимость получена при сканировании изображения образца участком в $4 \times 4$ рх через центр оптической неоднородности (рис. 3,c), образованной до старта трещины.

Спекловые изображения регистрировали по схеме рис. 2, а. Опираясь на результаты, приведенные на рис. 5, зависимость можно рассматривать как симметричную относительно начала координат. При приближении координаты $x$ к нулю зависимость $\eta(x)$ уменьшается от значения, близкого к единице, до минимума, затем в центре неоднородности величина $\eta$ возрастает до значения, близкого к единице. Такую особенность зависимости $\eta(x)$ можно объяснить, используя формулу (7). Действительно, переменной величиной в формуле (7) является разность оптических путей пар волн, усредненная по пространству (по областям диаметром $2 a_{s}$ ) и времени. Из соображений симметрии можно предположить, что в центре неоднородности указанная разность равна нулю. В таком случае косинус в формуле (1) будет равен единице, и $\eta$ будет зависеть только от величин $k_{11}$ и $k_{22}$. Отсюда следует, что они имеют значения, близкие к нулю. Следовательно, изменения показателя преломления среды на стадии предразрушения можно рассматривать не как случайный, а детерминированный процесс, который характеризуется величиной $\eta$, изменяющейся по закону косинуса.

Для количественной оценки изменения показателя преломления $n(x)$ по формуле (7) нами был взят образец с усталостной трещиной длиной $1.4 \mathrm{~mm}$, длина трещины была приблизительно одинаковой по толщине образца. Спекловые изображения были получены по схеме, представленной на рис. 2, a, первый кадр был зарегистрирован сразу после старта трещины, а второй перед остановкой испытания на усталость (рис. 6, a). Подобный образец был выбран для обеспечения ци- линдрической симметрии по оси $o x$ в распределении показателя преломления среды.

На рис. 6, а приведен участок спеклового изображения, соответствующий второму кадру, на рис. $6, b$ показано распределение величины $\eta$ по участкам размером $10 \times 10$ рх. На рис. 6, $a$ черной рамкой показан один из участков прямоугольной формы размером $10 \times 100$ рх, для которого далее производилось вычисление величины $\eta$. Белыми линиями обозначена область, в окрестностях которой производилось определение зависимости $n(x)$.

Зависимость $n(x)$ определяли в следующей последовательности. Область, показанная пунктиром на рис. 6, $a$ светлой рамкой, была разделена на участки размером 10 рх по горизонтали и 100 рх по вертикали. После этого для указанных участков по формуле (1) вычислялись значения $\eta$. Зависимость $\eta(x)$ приведена на рис. 7 , координата $x$ соответствует левому краю каждого участка $10 \times 100 \mathrm{px}$.

Затем с использованием формулы (8) находили величину

$$
\Delta n=n-n_{0}=\frac{\lambda}{2 \pi L} \arccos \left(\eta_{1}\right),
$$

где $n_{0}$ - показатель преломления на границе оптической неоднородности, равный $1.49, \eta_{1}$ - коэффициент корреляции, соответствующий первому участку. По формуле (12) можно определить значение показателя преломления $n$ на расстоянии $\Delta x$ от левой границы участка по оси ox. Мы приняли, что значение $\Delta x$ равно линейному разрешению линзы, равному $10 \mu \mathrm{m}$. Соображения об обоснованности такого решения приведены ниже в разделе „Обсуждение“. Из предположения о том, что на любом участке градиент $\partial n / \partial x$ есть константа, следует, что на границе между первым и вторым участками показатель преломления $n_{1}$ можно найти по формуле

$$
n_{1}=n_{0}-\frac{X}{\Delta x} \times \frac{\lambda}{2 \pi L} \arccos \left(\eta_{1}\right),
$$

где $X$ - размер участка по оси $о x$ в плоскости объекта. Подобным же образом получаем, что показатель преломления $n_{2}$ на границе между вторым и третьим участками определяется формулой

$$
n_{2}=n_{1}-\frac{X}{\Delta x} \times \frac{\lambda}{2 \pi L} \arccos \left(\eta_{2}\right) .
$$

Аналогичным образом определяли показатели преломления на границе других участков. Для перехода от показателя преломления к плотности использовали формулу Лоренц.Лорентца

$$
\frac{\left(n^{2}-1\right)}{\rho\left(n^{2}+2\right)}=\bar{r},
$$

где $\bar{r}-$ удельная преломляющая способность использованного нами оргстекла. Значение $\bar{r}$, равное $0.32 \mathrm{~cm}^{3} / \mathrm{kg}$, определили экспериментально на образце размером 

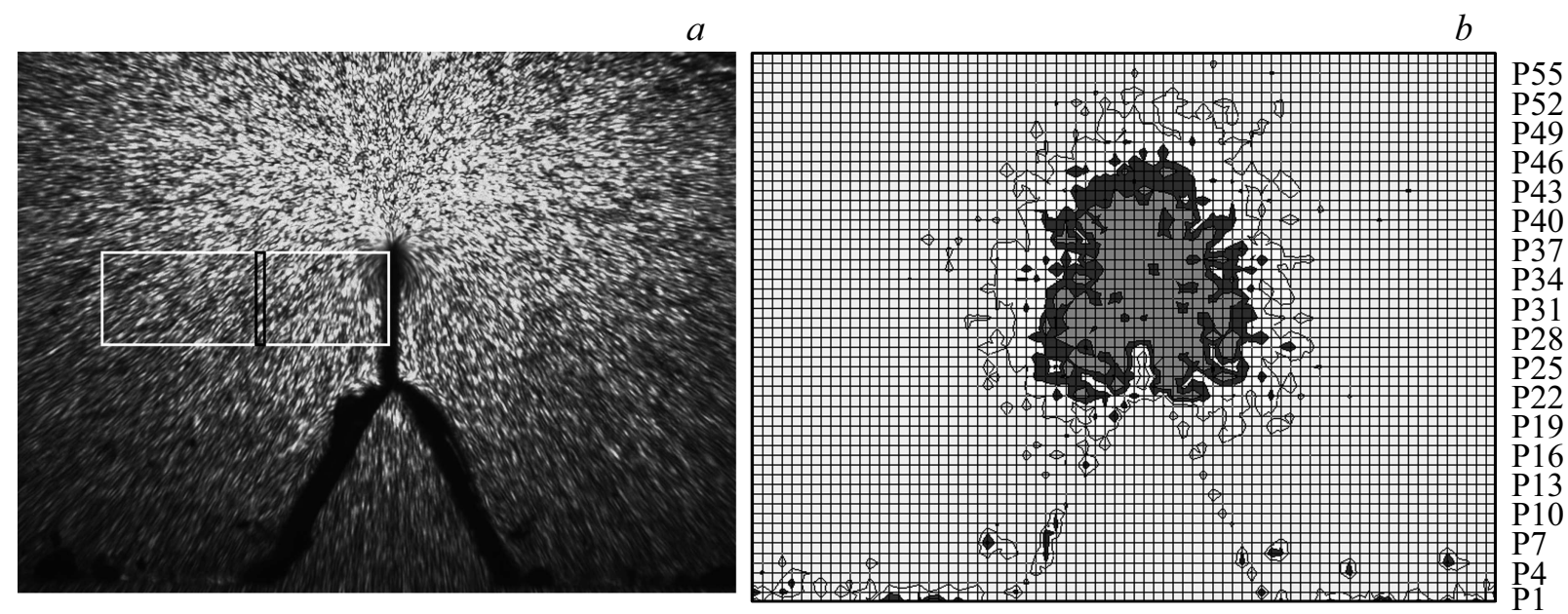

1591317212529333741454953576165697377

ㅁ $0.75-1.00 \quad \square 0.25-0.50$

$0.50-0.75 \square 0-0.25$

Рис. 6. Спекловое изображение образца с трещиной $(a)$ и поле коэффициентов корреляции $\eta$ фрагментов спекловых изображений $(b)$.

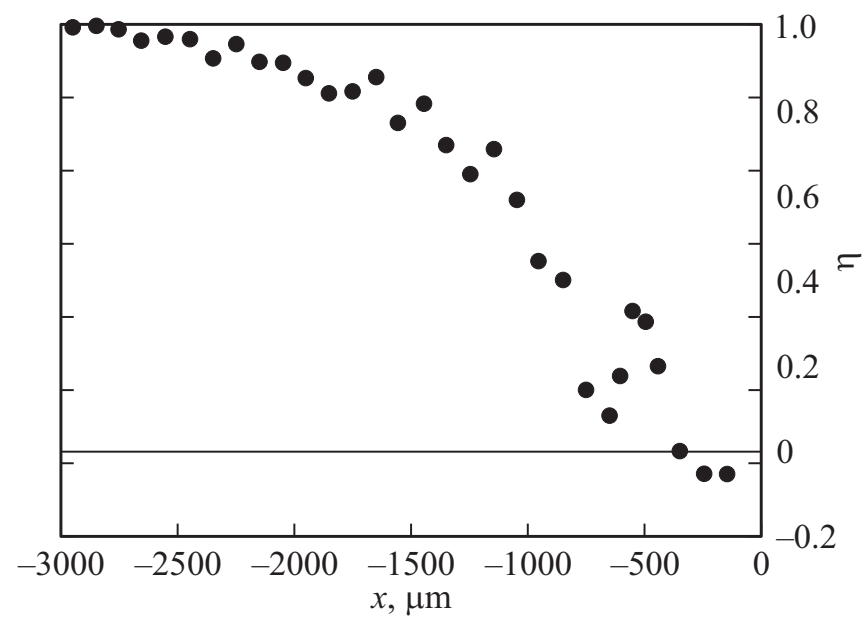

Рис. 7. Зависимость коэффициента корреляции $\eta$ от координаты $x$.

$5 \times 10 \times 20 \mathrm{~mm}$. Величину $n$, входящую в последнюю формулу, мы определяли поляризационно-оптическим методом, описанным выше в разделе „Оптическая эллипсометрия“", а плотность - по объему и массе образца. Массу образца находили путем взвешивания.

На рис. 8 приведены совмещенные зависимости $\rho(x)$, найденные на участке, показанном на рис. 6, $a$ белыми линиями. Квадратами обозначены данные, полученные по спекловым изображениям, зарегистрированным при испытании на усталость, кружки - данные поляризационного метода, треугольниками показаны значения, полученные также по спекловым изображениям образца, но через полгода после испытания на усталость.

Для получения последних результатов образец помещали на платформу моторизованного транслятора и освещали по схеме на рис. 2,a. После регистрации первого спеклового изображения образец перемещали по оси $о x$ на расстояние, превышающее размер зоны необратимых процессов, и регистрировали второе спекловое изображение. Далее выбирали такую же область рядом с изображением трещины, как и показанный большим белым прямоугольником на рис. 6, $a$, затем вновь разбивали эту область на участки размером $10 \times 100$ рх. По описанной выше процедуре находили значения показателя преломления и плотности на границах участков.

\section{Обсуждение}

Выше в формулах (13) и (14) величина $\Delta x$ была взята равной линейному разрешению $2 a_{s}$ линзы 5 , показанной на рис. 2. Для обоснования такого выбора рассмотрим материалы, опубликованные ранее в работах $[11,19]$. В этих статьях изучены особенности динамики спеклов, возникающие в плоскости изображения пластически деформируемых диффузно отражающих объектов. При растяжении образцов и периодических деформациях в условиях многоцикловой усталости были обнаружены квазипериодические изменения цифровых значений интенсивности. Было установлено, что подобные изменения интенсивности излучения соответствовали локальным поворотам участков поверхности. Найденное явление было объяснено многолучевой интерференцией волн, отраженных от точечных центров рассеяния, расположенных в области диаметром $2 a_{s}$. Пусть для определенности локальный поворот поверхности происходит вокруг оси оу. Согласно работам [11,19], следует принять во внимание центры рассеяния, $y$-координаты которых случайны, но по оси ох они расположены на одинаковом расстоянии друг от друга. Начальные фазы 


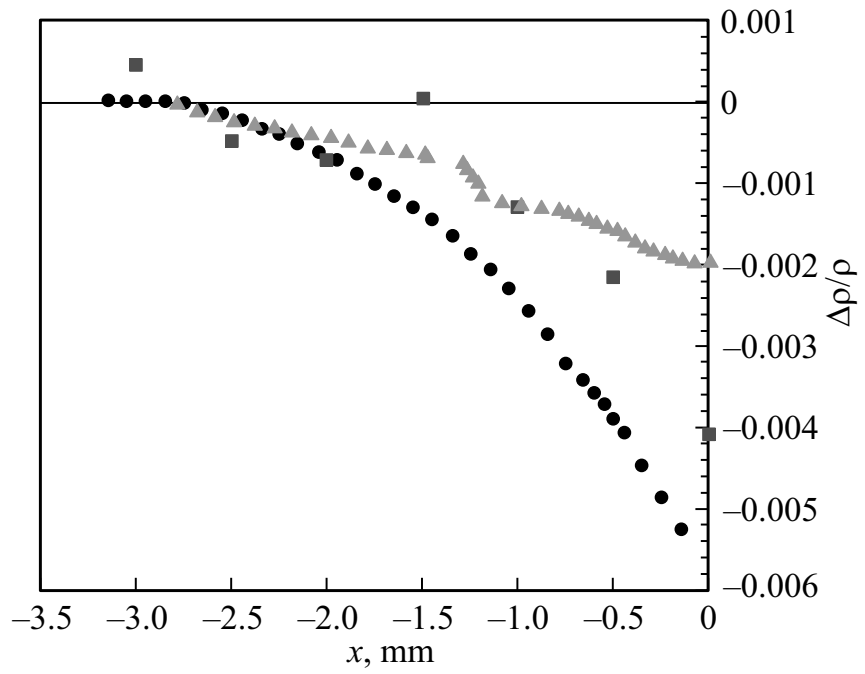

Рис. 8. Относительные изменения плотности вблизи трещины: - - во время испытания на усталость, $\mathbf{\square}$ - эллипсометрия, $\Delta$ - найденные по перемещению образца.

волн, отраженных от таких центров, должны быть одинаковыми. Тогда при жестком повороте поверхности в соответствующей точке наблюдения возникнет квазипериодическое изменение интенсивности. Это изменение эквивалентно изменению, возникающему при интерференции двух волн, распространяющихся от двух центров рассеяния, расположенных на противоположных краях области диаметром $2 a_{s}$. Аналогичная ситуация имеет место и в случае, если объектом исследования является тонкая пластина из органического стекла, расположенная вблизи неподвижного диффузора, а в области диаметром $2 a_{s}$ изменяется градиент показателя преломления. Различие заключается в том, что множество волн со случайными амплитудами и фазами теперь проходят через прозрачный объект, остальные рассуждения остаются в силе.

Использованные в работе методы оценки изменения показателя преломления $n$ не лишены недостатков. Главным недостатком поляризационного метода в настоящее время является относительно большая область усреднения (около $1 \mathrm{~mm}$ ), а спекловый метод не позволяет оценить изменения $n$ в непосредственной близости от трещины. Устранение этих недостатков может быть предметом дальнейших исследований. Тем не менее использование указанных методов позволило установить, что максимальные относительные необратимые изменения плотности, возникающие при усталости оргстекла, не меньше чем $2 \cdot 10^{-3}$. Эта величина согласуется с данными [20] о предельных значениях относительного изменения плотности оргстекла $\left(10^{-3}-10^{-2}\right)$ при выдержке образцов при постоянной нагрузке.

Анализируя результаты, представленные на рис. 8, можно сделать вывод, что наибольшие изменения плотности вблизи трещины зафиксированы при испытании на усталость, минимальные изменения получены при перемещении образца после полугодовой выдержки, а промежуточные данные показал метод эллипсометрии. Данный результат авторы связывают с релаксационными процессами в оргстекле. Действительно, измерения на эллипсометре были проведены через 3 месяца после испытания на усталость, а эксперимент по перемещению образца был проведен через полгода. При эллипсометрическом исследовании было обнаружено, что через неделю наблюдается заметный поворот плоскости поляризации света, прошедшего через объект. Данный факт свидетельствует о релаксации остаточных напряжений, вызванных изменением плотности.

Приведенная выше оценка изменения плотности, найденный размер области локализации повреждений, обнаружение остаточных напряжений имеют важное значение для выявления общих закономерностей перехода разных материалов из первоначально сплошного в деструктивное состояние при многоцикловой усталости. Сравнение выявленных в настоящей работе особенностей зарождения трещины в оргстекле с особенностями ее зарождения в металле, рассмотренными нами ранее в работах $[10,11,13]$, показывает, что эти особенности имеют общие черты, имеется даже совпадение в некоторых деталях. Отметим, что образцы из металла и оргстекла имели одинаковую форму и одинаковые размеры, схемы нагружения также были одинаковыми. Так, при многоцикловой усталости первые заметные необратимые изменения рельефа поверхности в металле и плотности в оргстекле возникают не на вершине надреза, а примерно на одинаковом расстоянии от края надреза. Размеры зон зарождения трещин $(50-100 \mu \mathrm{m})$ и их местоположение совпадают. Отличие заключается в том, что в металле имеется механизм диссипации энергии, связанный с движением дислокаций. Вследствие этого необратимые деформации проявляются в виде изменения формы образца, а именно утяжки диаметром около $500 \mu \mathrm{m}[10,11]$ вблизи надреза. В оргстекле такого механизма нет. Необратимые деформации в нем проявляются в виде изменения объема, плотности. Предельное относительное изменение плотности около $6 \cdot 10^{-3}$, найденное нами, по видимому, можно рассматривать как предельное значение деформации, соответствующее старту трещины.

В работе [14] было предложено объяснение тому факту, что для металлов первые локализованные изменения величины $\eta$ наблюдаются не на вершине надреза, а на некотором расстоянии от вершины. Согласно предложенной в работе [14] гипотезе, на определенной стадии циклических деформаций при увеличении напряжений вблизи надреза в малой области возникают необратимые процессы, способствующие появлению несовместных деформаций (при мысленном разбиении малой области на мелкие кусочки, их деформировании и последующей сборке они не возвращаются в первоначальное положение). Тогда при как угодно малой разгрузке окружающий материал сжимает эту область. При полной разгрузке 
образца вблизи надреза возникают сжимающие остаточные напряжения, а на некотором расстоянии от него наиболее опасные растягивающие остаточные напряжения. Далее при циклическом нагружении материал вблизи надреза будет периодически деформироваться в условиях сжатия-сжатия, на некотором расстоянии - в условиях растяжения растяжения, а в промежутке между ними - в условиях растяжения-сжатия. Данные, полученные нами в оргстекле, указывают на корректность выдвинутой гипотезы. Нами прямыми наблюдениями в реальном времени зафиксировано наличие несовместных деформаций - необратимых изменений плотности в локальных областях, количественно определено максимальное изменение плотности. Наличие остаточных напряжений подтверждено косвенным образом по их релаксации, обнаруженной по вращению плоскости поляризации света и по изменению распределения величины $\eta$ с течением времени.

Полученные данные согласуются также с современными представлениями о многоцикловой усталости полимеров [21], в том числе полиметилметакрилата, базирующиеся на кинетической концепции разрушения твердых тел С.Н. Журкова [20,22,23]. Согласно этим представлениям, при выдержке образцов полимера как при постоянной, так и при переменной нагрузке в результате хаотического движения атомов и молекул в некоторый момент возникает смещение атомов, превышающее критическое значение, атомная связь разрушается. Методами инфракрасной спектроскопии и малоуглового рассеяния рентгеновских лучей установлено, что уже на ранних стадиях усталости в результате разрыва атомных связей в оргстекле формируются дискообразные дефекты диаметрами в десятки нанометров. Концентрация хаотично расположенных дефектов растет по мере увеличения числа циклов нагружения, при этом плотность полимера уменьшается. Поскольку размеры дефектов малы по сравнению с длиной волны использованных нами лазеров, то спекловый метод и метод эллипсометрии регистрируют макроскопические изменения показателя преломления, вызванные усталостной деградацией оргстекла.

Полученные нами данные позволяют сделать вывод о преимуществах использованного нами метода перед традиционными спекл-голографическими методами [2426] при определении отношения разности показателя преломления $\Delta n$ прозрачной среды или разности перемещений $\Delta u$ точек поверхности объекта к базе их измерения $\Delta \tilde{x}$. Как было указано выше, квазипериодическое изменение интенсивности излучения в некоторой точке плоскости изображения вызывается изменениями величин $\Delta n$ или $\Delta u$ на базе $\Delta \tilde{x}$, равной линейному разрешению линзы $\Delta x$. Пусть для определенности, значения $\Delta n, \Delta u, \Delta x$, а следовательно, и $\Delta n / \Delta \tilde{x}, \Delta u / \Delta \tilde{x}$ определяются с погрешностью порядка $1 \%$. Традиционные методы позволяют определять не разности значений, а сами значения $n$ и $u$, усредненные по области размером $\Delta x$. Тогда при использовании традиционных методов для определения величин $\Delta n / \Delta \tilde{x}, \Delta u / \Delta \tilde{x}$ с указанной точностью база $\Delta \tilde{x}$ должна быть на два порядка больше величины $\Delta x$. В наших опытах значения $\Delta x$ и $\Delta \tilde{x}$ были порядка $10 \mu \mathrm{m}$. Следовательно, для традиционных методов при прочих равных условиях, $\Delta \tilde{x} \cong 1 \mathrm{~mm}$, что и имеет место на практике.

В традиционных методах измерения проводятся путем регистрации порядка интерференционных или корреляционных полос. Предельная чувствительность методов при измерениях в реальном времени определяется погрешностью $\Delta N$ определения порядка полос $N$. При работе в реальном времени трудно использовать специальные методы определения $N$, поэтому можно принять $\Delta N \cong 0.1-0.3$, что соответствует значениям $\Delta u$ и $\Delta n l$ ( $l$ - толщина объекта), равным примерно $30-100 \mathrm{~nm}$. В то же время предельная чувствительность нового метода, согласно [10,13], это единицы нанометров.

Таким образом, при анализе деформаций объектов новый метод по пространственному разрешению и чувствительности значительно превосходит указанные выше традиционные когерентно-оптические методы измерения и контроля. Этот вывод справедлив и для сдвиговых вариантов методов. Данное преимущество позволяет успешно использовать метод в условиях многоциклового нагружения объектов для определения предельных значений необратимых деформаций, локализованных на малых участках. Контролируя скорость изменения деформаций, по их предельному значению можно оценить время до появления разрушения. В тех случаях, когда прямое применение данного оптического метода невозможно, он может быть использован для модернизации традиционных методов контроля с целью существенного уменьшения области усреднения до величин порядка $10 \mu \mathrm{m}$. Предложенный нами метод может быть использован для обнаружения малых областей локализованных усталостных повреждений материалов.

\section{Выводы}

На призматических образцах с острым надрезом, изготовленных из оргстекла марки ACRUMA, периодически деформируемых трехточечным изгибом, методами динамической спекл-интерферометрии и эллипсометрии изучены особенности изменения показателя преломления и плотности. При зондировании образца спеклнеоднородной волной наблюдениями в режиме реального времени по нормали к поверхности и под некоторым углом к поверхности показано, что первые признаки необратимых процессов наблюдаются в виде оптических неоднородностей размером в десятые доли миллиметра. Они возникают на участках, расположенных по глубине примерно в центре образца, и на расстоянии нескольких сот микрон от вершины надреза. Затем подобные участки появляются на том же расстоянии от вершины, но на разных расстояниях от поверхности. Деградация материала происходит в областях, соединяющих участки 
с вершиной надреза. Формирование трещины завершается объединением этих областей. При старте трещины размер зоны необратимых деформаций увеличивается на порядок и занимает область размером в несколько миллиметров.

По изменению коэффициента корреляции участков спекловых изображений и методом эллипсометрии показано, что результатом усталостного повреждения оргстекла является уменьшение плотности; максимальное относительное изменение ее составляет не менее $2 \cdot 10^{-3}$.

Преимуществом предложенного метода является возможность контроля необратимых изменений показателя преломления прозрачного объекта и относительного перемещения точек поверхности непрозрачных тел на малых участках порядка $10 \mu \mathrm{m}$. Данное обстоятельство может быть базой для создания методик, позволяющих при многоцикловой усталости материалов по изменению коэффициента корреляции фрагментов спекловых изображений в режиме реального времени определять скорость изменения относительного перемещения точек поверхности непрозрачных тел или скорость изменения показателя преломления прозрачного объекта. В этом случае появляется возможность по предельным значениям этих величин оценивать время до старта трещины.

\section{Благодарности}

Авторы выражают благодарность к.ф.м.н Шредер Е.И. и д.т.н. Гладковскому С.В. за замечания, которые способствовали улучшению данной работы.

\section{Финансирование работы}

Работа выполнена с использованием оборудования ЦКП „Пластометрия“ ИМАШ УрО РАН в рамках государственного задания (тема № АAАА-А18118020790148-1).

\section{Конфликт интересов}

Авторы заявляют, что у них нет конфликта интересов.

\section{Список литературы}

[1] Тупикин Д.А. // Контроль. Диагностика. 2003. № 11. С. 53.

[2] Новиков И.И., Ермишин В.А. Физическая механика реальных материалов. М.: Наука, 2004. 328 с.

[3] Lasar J., Hola M., Cip O. // Book of abstracts. Conference PhotoMechanics 2015, Delft, Netherlands, P. 64.

[4] Степнов М.Н., Зинин А.В. Прогнозирование характеристик сопротивления усталости материалов и элементов конструкций. М.: Инновационное машиностроение, 2016. 391 c. ISBN 978-5-9907308-0-9 ББК 30.121

[5] Терентьев В.Ф. Усталость металлических материалов. М.: Наука, 2002. 248 с.

[6] Голографические неразрушающие исследования / Под ред. Эрфа Р.К. М.: Машиностроение, 1985. 245 с.
[7] Marom E., Muller R.K. // Intern. J. Nondestructive Testing. 1971. V. 3. P. 171.

[8] Козубенко В.П., Потиченко В.А, Бородин Ю.С. // Проблемы прочности. 1989. № 7. С. 103.

[9] Vladimirov A.P. // AIP Conference Proceedings. 2014. V. 1600. P. 237.

[10] Владимиров А.П., Каманщев И.С., Ищенко А.В., Веселова В.Е., Горкунов Э.С., Гладковский С.В., Задворкин С.М. // Деформ. и разр. матер. 2015. № 1. С. 21.

[11] Владимиров А.П., Каманщев И.С., Веселова В.Е., Горкунов Э.С., Гладковский С.В. // ЖТФ. 2016. Т. 86. В. 4. С. 85.

[12] Vladimirov A.P. // AIP Conference Proceedings. 2016. V. 1740. P. 040004.

[13] Vladimirov A.P. // Optical Engineering. 2016. V. 55. N 12. P. 121727.

[14] Владимиров А.П., Поносов Ю.С. // Вестн. Пермского национального исследовательского политехнического университета. Механика. 2018. № 3. С. 138.

[15] Vladimirov A.P., Druzhinin A.V., Malygin A.S., Mikitas K.N. // Proc. SPIE. 2012. V. 8337. P. 83370C

[16] Горшков М.М. Эллипсометрия. М.: Советское радио, 1974. $200 \mathrm{c}$.

[17] Основы эллипсометрии / Под ред. Ржанова А.В. М.: Наука, 1979. $424 \mathrm{c}$.

[18] Аззам Р., Башара Н. Эллипсометрия и поляризованный свет. М.: Мир, 1981. 583 с.

[19] Vladimirov A.P. // AIP Conference Proceedings. 2012. V. 1457. P. 459.

[20] Журков С.Н., Марихин В.А., Слуцкер А.И. // ФТТ. 1959. T. 1. B. 7. C. 11594.

[21] Encyclopedia of Polymer Science and Technology, 12 Vol. Set. / Ed. by H.F. Mark. Wiley Interscience, 3rd edn, 2004. P. 197.

[22] Журков С.Н. // Вестн. АН СССР. 1968. С. 46.

[23] Журков С.Н., Слуцкер А.И., Марихин В.А. // ФТТ. 1959. T. 1. B. 11. C. 1752.

[24] Александров Е.Б., Бонч Бруевич А.М. // ЖТФ. 1967. Т. 64. B. 2. C. 360.

[25] Leendertz J.A. // J. Phys. E: Sci. Instrum. 1970. N 3. P. 214.

[26] Владимиров А.П., Микушин В.И., Лисин А.Л. // Письма в ЖТФ. 1999. В. 24. С. 88 